\title{
Natrinema versiforme sp. nov., an extremely halophilic archaeon from Aibi salt lake, Xinjiang, China
}

\author{
Huawei Xin, ${ }^{1,2}$ Takashi Itoh, ${ }^{2}$ Peijin Zhou, ${ }^{1}$ Ken-ichiro Suzuki, ${ }^{2}$ \\ Masahiro Kamekura ${ }^{3}$ and Takashi Nakase ${ }^{2}$
}

1 The Institute of Microbiology, Chinese Academy of Sciences (CAS), Beijing 100080, PR China

2 Japan Collection of Microorganisms, RIKEN (The Institute of Physical and Chemical Research), Wako-shi, Saitama 351-0198, Japan

3 Noda Institute for Scientific Research, 399 Noda, Noda-shi, Chiba 278-0037, Japan

\author{
Author for correspondence: Takashi Itoh. Tel: +81 48467 9560. Fax: +81484624617. \\ e-mail: ito@jcm.riken.go.jp
}

\begin{abstract}
A novel extremely halophilic archaeon, strain $\mathrm{XF10}^{\top}$, was isolated from a salt lake in China. This organism was neutrophilic, non-motile and pleomorphic, and was rod, coccus or irregularly shaped. It required at least $1.5 \mathrm{M} \mathrm{NaCl}$ for growth and grew in a wide range of $\mathrm{MgCl}_{2}$ concentrations (0.005-0.5 M). Lipid extract of whole cells contained two glycolipids with the same chromatographic properties as two unidentified glycolipids found in the two described Natrinema species, Natrinema pellirubrum and Natrinema pallidum. Phylogenetic analysis based on 16S rDNA sequence comparison revealed that strain XF10' clustered with the two described Natrinema species and several other strains (strains T5.7, GSL-11 and Haloterrigena turkmenica JCM 9743) with more than $98.1 \%$ sequence similarities, suggesting that strain XF10' belongs to the genus Natrinema. Comparative analysis of phenotypic properties and DNA-DNA hybridization between strain XF10 and the Natrinema species supported the conclusion that strain XF10 is a novel species within the genus Natrinema. The name Natrinema versiforme sp. nov. is proposed for this strain. The type strain is XF10 ${ }^{\top}\left(=J C M 10478^{\top}=A S\right.$ $1.2365^{\top}=$ ANMR 0149').
\end{abstract}

Keywords: Natrinema versiforme sp. nov., halobacteria, archaea

\section{INTRODUCTION}

Halobacteria (the family Halobacteriaceae; Grant \& Larsen, 1989) are a diverse group of extremely halophilic archaea that require at least $1.5 \mathrm{M} \mathrm{NaCl}$ for growth. In the last few years, the numbers of halobacterial genera and species have increased rapidly. Several new genera, e.g. Halogeometricum (MontalvoRodríguez et al., 1998) and Natronorubrum (Xu et al., 1999), have been created to accommodate newly isolated strains, and the others have been proposed by re-evaluation of misidentified or insufficiently described strains, e.g. Natrinema (McGenity et al., 1998) and Haloterrigena (Ventosa et al., 1999).

Abbreviations: PG, phosphatidylglycerol; PGP-Me, phosphatidylglycerophosphate-methyl ester; PGS, phosphatidylglycerosulfate; $S_{2}$-DGD-1, 2,6$\mathrm{HSO}_{3}-\mathrm{Man} p-\alpha(1 \rightarrow 2)-\mathrm{Gl} c p-\alpha(1 \rightarrow 1)$-sn-glyceroldiether; TMAO, trimethylamine $\mathrm{N}$-oxide.

The DDBJ accession number for the 16S rDNA sequence of Natrinema versiforme $\mathrm{XF}^{\top} 0^{\top}$ is $\mathrm{AB} 023426$.
Hypersaline environments are commonly found in China. In addition to many coastal salterns, a number of salt lakes, soda lakes and salt-rich deserts are located in the west to northwest part of China, i.e. from Inner Mongolia, Qinghai Province, to Xinjiang and Tibet Autonomous Regions. From these saline environments, a number of halobacteria have been isolated, including strains A5 and B2, which have been shown to be related to the genus Haloarcula based on polar lipid composition and 16S rDNA sequence (Zhou et al., 1994; Xu et al., 1995), strain HAM-2, which has been shown to be a close relative of Natrialba magadii on the basis of 16S rDNA sequence (Tian et al., 1997; Xu et al., 1999), two species of the genus Natronorubrum (Natronorubrum bangense and Natronorubrum tibetense) (Xu et al., 1999), and some incompletely characterized strains (Wang et al., 1984; Zhou et al., 1990). Isolation of novel strains of the genera Haloarcula, Natrialba and Natrinema $(\mathrm{H}$. Xin and others, unpublished work) has also exemplified the wide diversity of halobacteria in the hypersaline habitats in China. 


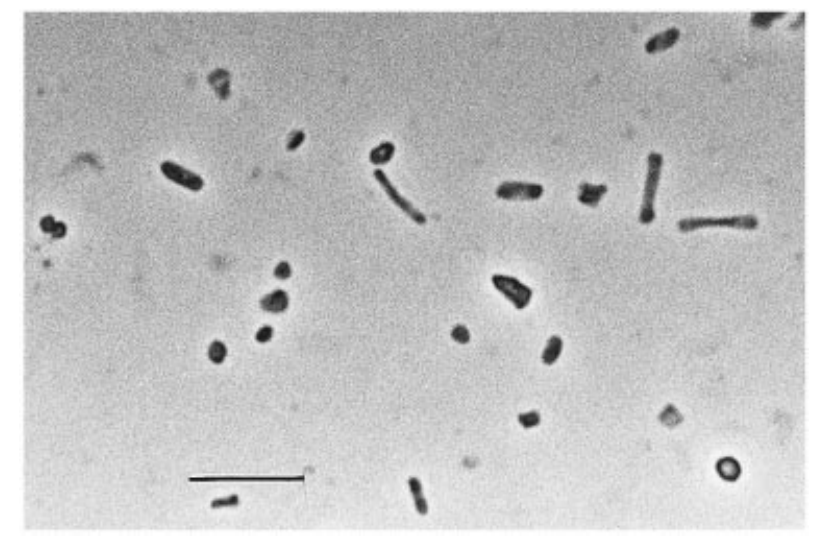

Fig. 1. Phase-contrast micrograph of strain $X F 10^{\top}$. Cells were pleomorphic and rod, coccus or irregularly shaped. Bar, $10 \mu \mathrm{m}$.

In this paper, a novel halobacterial isolate, $\mathrm{XF} 10^{\mathrm{T}}$, which was isolated from a salt lake in the northwest part of China, is described.

\section{METHODS}

Isolation procedure, strains and growth conditions. Strain $\mathrm{XF} 10^{\mathrm{T}}$ was isolated from clay collected from the shallow near-edge floor of Aibi salt lake in Xinjiang Autonomous Region, China. After enrichment of the sample in Sehgal and Gibbons medium (Sehgal \& Gibbons, 1960) at $37^{\circ} \mathrm{C}$ with shaking for 1-2 weeks, a pure culture was obtained by plating serial dilutions of enrichment cultures and repeated transfers of separate colonies on agar plates of the same medium. The purity of the strain was checked by colony morphology and randomly amplified polymorphic DNA patterns of total DNAs derived from different colonies on the agar plate. The growth medium used for the following studies contained $\left(\mathrm{l}^{-1}\right): 5 \mathrm{~g}$ Casamino acids (Difco); $5 \mathrm{~g}$ yeast extract (Difco); $1 \mathrm{~g}$ sodium glutamate; $3 \mathrm{~g}$ trisodium citrate dihydrate; $30 \mathrm{~g} \mathrm{MgCl}_{2} .6 \mathrm{H}_{2} \mathrm{O} ; 5 \mathrm{~g} \mathrm{~K} \mathrm{SO}_{4} ; 36 \mathrm{mg}$ $\mathrm{FeCl}_{2} .6 \mathrm{H}_{2} \mathrm{O} ; 0 \cdot 36 \mathrm{mg} \mathrm{MnCl} \mathrm{M}_{2} .4 \mathrm{H}_{2} \mathrm{O}$; and $220-250 \mathrm{~g} \mathrm{NaCl}$ ( $\mathrm{pH} 7 \cdot 0)$. Agar slants and plates were prepared by adding $20 \mathrm{~g}$ agar $1^{-1}$. The strain was maintained on agar slants for short periods (several months) or stored in growth medium with glycerol (final $20 \%, \mathrm{v} / \mathrm{v}$ ) at $-80^{\circ} \mathrm{C}$ for long-term preservation. Haloterrigena turkmenica JCM 9743 (for genus and species designation, see Discussion; deposited in JCM by M. Kamekura in 1995), Haloterrigena turkmenica JCM $9101^{\mathrm{T}}$ (=VKM B-1734 ${ }^{\mathrm{T}}$; transferred from VKM to JCM in 1993), Natrinema pallidum JCM $8980^{\mathrm{T}}$ (= NCIMB $777^{\mathrm{T}}$; transferred from NCIMB to JCM in 1993) and Natrinema pellirubrum JCM $10476^{\mathrm{T}}$ ( = NCIMB $786^{\mathrm{T}}$; transferred from NCIMB to JCM in 1999) were used as reference strains and cultivated in the above growth medium with $20 \mathrm{~g}$ $\mathrm{MgSO}_{4} \cdot 7 \mathrm{H}_{2} \mathrm{O} \mathrm{l}^{-1}$ and $2 \mathrm{~g} \mathrm{KCl}^{-1}$ (instead of $\mathrm{MgCl}_{2} \cdot 6 \mathrm{H}_{2} \mathrm{O}$ and $\mathrm{K}_{2} \mathrm{SO}_{4}$ ), and $200 \mathrm{~g} \mathrm{NaCl}^{-1}$. If not specified, strains were cultivated at $37^{\circ} \mathrm{C}$ with shaking at 180 r.p.m. in $500 \mathrm{ml}$ Erlenmeyer flasks containing $100 \mathrm{ml}$ medium. Inoculated agar plates were wrapped in plastic bags and incubated at $37^{\circ} \mathrm{C}$.

Morphology and growth characteristics of strains. Cells were observed under a phase-contrast light microscope (Optiphot-2; Nikon). Gram staining was performed with acetic-acid-fixed cells as described by Dussault (1955). Cell lysis was observed by diluting dense cell suspensions with the diluted medium or distilled water. Growth ranges and optima of $\mathrm{NaCl}$ and $\mathrm{MgCl}_{2}$ levels were determined using growth medium containing various concentrations of $\mathrm{NaCl}$ $(1 \cdot 2-5 \cdot 2 \mathrm{M})$ and $\mathrm{MgCl}_{2}(0 \cdot 005-0 \cdot 5 \mathrm{M})$, respectively. Various buffer systems were employed in the determination of growth $\mathrm{pH}(50 \mathrm{mM}$ of each) : MES ( $\mathrm{pH} 5 \cdot 5-6 \cdot 5)$, PIPES (pH 6.5-7.5), HEPES (pH 7.0-8.0), Tricine $(\mathrm{pH} 7 \cdot 5-9 \cdot 0)$ and CHES $(\mathrm{pH}$ $9 \cdot 0-10 \cdot 0)$. Growth temperature was determined in the range $4-60{ }^{\circ} \mathrm{C}$ by using a temperature gradient incubator (model TN-3; ADVANTEC). Growth rate was determined by measuring culture turbidity at $660 \mathrm{~nm}$.

Nutrition. Anaerobic growth in the presence of arginine, DMSO, trimethylamine $N$-oxide (TMAO) and nitrate ( $5 \mathrm{~g}$ $1^{-1}$ of each) was determined in rubber-stoppered tubes completely filled with the growth medium in the dark for 1-3 weeks and compared to growth on medium without the test compounds. Reduction of nitrate was detected by using the sulfanilic acid and $\alpha$-naphthylamine reagent (Smibert \& Krieg, 1981). Formation of gas from nitrate was detected by using Durham tubes under anaerobic conditions.

To estimate the utilization of various carbohydrates as carbon and energy sources, the basal medium $[0 \cdot 1 \mathrm{~g}$ yeast extract $1^{-1}$ (Difco), 0.5 $\mathrm{g} \mathrm{NH}_{4} \mathrm{Cl}^{-1}, 0.05 \mathrm{~g} \mathrm{KH}_{2} \mathrm{PO}_{4} 1^{-1}$, at pH $7 \cdot 0$ with $50 \mathrm{mM}$ HEPES] was supplemented with $10 \mathrm{~g}$ test carbohydrate $1^{-1}$. Production of acids from carbohydrates was tested in the basal medium supplemented with $0.5 \mathrm{~g}$ test substrate $1^{-1}$ without buffer. The cultures were incubated at $37^{\circ} \mathrm{C}$ without shaking for 2 weeks. Growth was determined visually and $\mathrm{pH}$ was measured with a $\mathrm{pH}$ electrode.

Biochemical tests. Tests for catalase and oxidase activities, formation of indole, and hydrolysis of starch, gelatin, casein and Tween 80 were performed according to the standard or modified procedures of Oren et al. (1997). Formation of sulfide was determined by incubating cells in the growth medium supplemented with elemental sulfur $\left(6.4 \mathrm{~g}^{-1}\right)$ or sodium thiosulfate $\left(\mathrm{Na}_{2} \mathrm{~S}_{2} \mathrm{O}_{3} .5 \mathrm{H}_{2} \mathrm{O}, 5 \cdot 0 \mathrm{~g} \mathrm{l}^{-1}\right)$ without shaking, and detecting sulfide with a strip of paper impregnated with $10 \%(\mathrm{w} / \mathrm{v})$ lead acetate solution.

Sensitivity to antimicrobial agents. Sensitivity to antimicrobial agents was determined in the growth medium containing each antimicrobial agents at $50 \mathrm{mg} \mathrm{l}^{-1}$ for at least 2 weeks. Antimicrobial agents used were ampicillin, anisomycin, bacitracin, chloramphenicol, erythromycin, neomycin, novobiocin, penicillin $\mathrm{G}$ and rifampicin.

Lipid analyses. Total lipids were extracted by the modified method of Kamekura (1993) and separated by TLC on Merck Kieselgel 60-HPTLC. For one-dimensional development, the solvent was chloroform/methanol/acetic acid/ water $(85: 22 \cdot 5: 10: 4, \mathrm{v} / \mathrm{v})$. For two-dimensional development, the solvents were chloroform/methanol/water $(65: 25: 4, \mathrm{v} / \mathrm{v})$ followed by chloroform/methanol/acetic acid/water $(80: 12: 15: 4, \mathrm{v} / \mathrm{v})$. Phospholipids were detected with the Zinzadze reagent of Dittmer \& Lester (1964). Glycolipids were detected by spraying the plate with $0.5 \%$ 1 -naphthol in methanol/water $(1: 1)$ and then with sulfuric acid/ethanol $(1: 1)$ followed by heating at $120^{\circ} \mathrm{C}$ for $5-10$ min; all the other polar lipids were detected by further heating of the plate at about $250{ }^{\circ} \mathrm{C}$ for several minutes (Ihara et al., 1997).

Sequencing of 16S rDNA. Total DNAs were extracted by the method of Cline et al. (1989). The 16S rRNA genes were amplified by PCR with the following forward and reverse primers: 5'-TCCGGTTGATCCTGCCG (positions 8-24 according to Escherichia coli numbering) and 5'-GGAGGTGATCCAGCCG (positions 1540-1525). The amplified 
16S rDNAs were cloned into pT7Blue T-vector (Novagen) and sequenced using the SequiTherm Long-Read Cycle Sequencing kit (Epicentre Technologies) on the ALFred DNA sequencer (Pharmacia Biotech). The sequence obtained was aligned with the other reported halobacterial 16S rDNA sequences by using the CLUSTAL w 1.7 program (Thompson et al., 1994). The phylogenetic tree was reconstructed by the neighbour-joining method (Saitou \& Nei, 1987) and was evaluated by bootstrap sampling (Felsenstein, 1985).

G $+\mathbf{C}$ content and DNA-DNA hybridization. $\mathrm{G}+\mathrm{C}$ content was determined by the HPLC method of Tamaoka (1994). DNA-DNA hybridization was assessed by the fluorometric method of Ezaki et al. (1989).

\section{RESULTS}

\section{Morphology and growth characteristics}

Cells of strain XF10 ${ }^{\mathrm{T}}$ growing exponentially under optimal condition were non-motile and pleomorphic, with rods, cocci or irregular shapes (Fig. 1). The pleomorphism was confirmed in media containing various concentrations of $\mathrm{NaCl}(2 \cdot 6-5 \cdot 2 \mathrm{M})$ or $\mathrm{MgCl}_{2}$ $(0 \cdot 005-0.5 \mathrm{M})$. Cell lysis occurred in the diluted medium containing less than $1.0 \mathrm{M} \mathrm{NaCl}$ or in distilled water. There were no gas vesicles formed inside cells. Cells stained Gram-negative. Colonies formed on agar plates were light-red, opaque, small and circular, $0.5-1.0 \mathrm{~mm}$ in diameter, and elevated. The strain grew at $1.5 \mathrm{M}$ to saturation of $\mathrm{NaCl}$ and grew optimally at 3.4-4.3 $\mathrm{M}$ (in the presence of $0.15 \mathrm{M} \mathrm{MgCl}_{2}$ ). The strain grew in a wide range of $\mathrm{MgCl}_{2}$ concentrations from 0.005 to $0.5 \mathrm{M}$ and grew optimally around $0 \cdot 15$ M. It was neutrophilic ( $\mathrm{pH} 6.0-8 \cdot 0)$ with an optimum $\mathrm{pH}$ at $6 \cdot 5-7 \cdot 0$. Growth occurred in the temperature range $20-53{ }^{\circ} \mathrm{C}$ with an optimum at $37-46{ }^{\circ} \mathrm{C}$. Under the optimal growth conditions $(3 \cdot 4-4 \cdot 3 \mathrm{M} \mathrm{NaCl}$, $0.15 \mathrm{M} \mathrm{MgCl}_{2}$, at $37{ }^{\circ} \mathrm{C}$ and $\mathrm{pH} 7 \cdot 0$ ), the doubling time was $11 \cdot 0 \mathrm{~h}$.

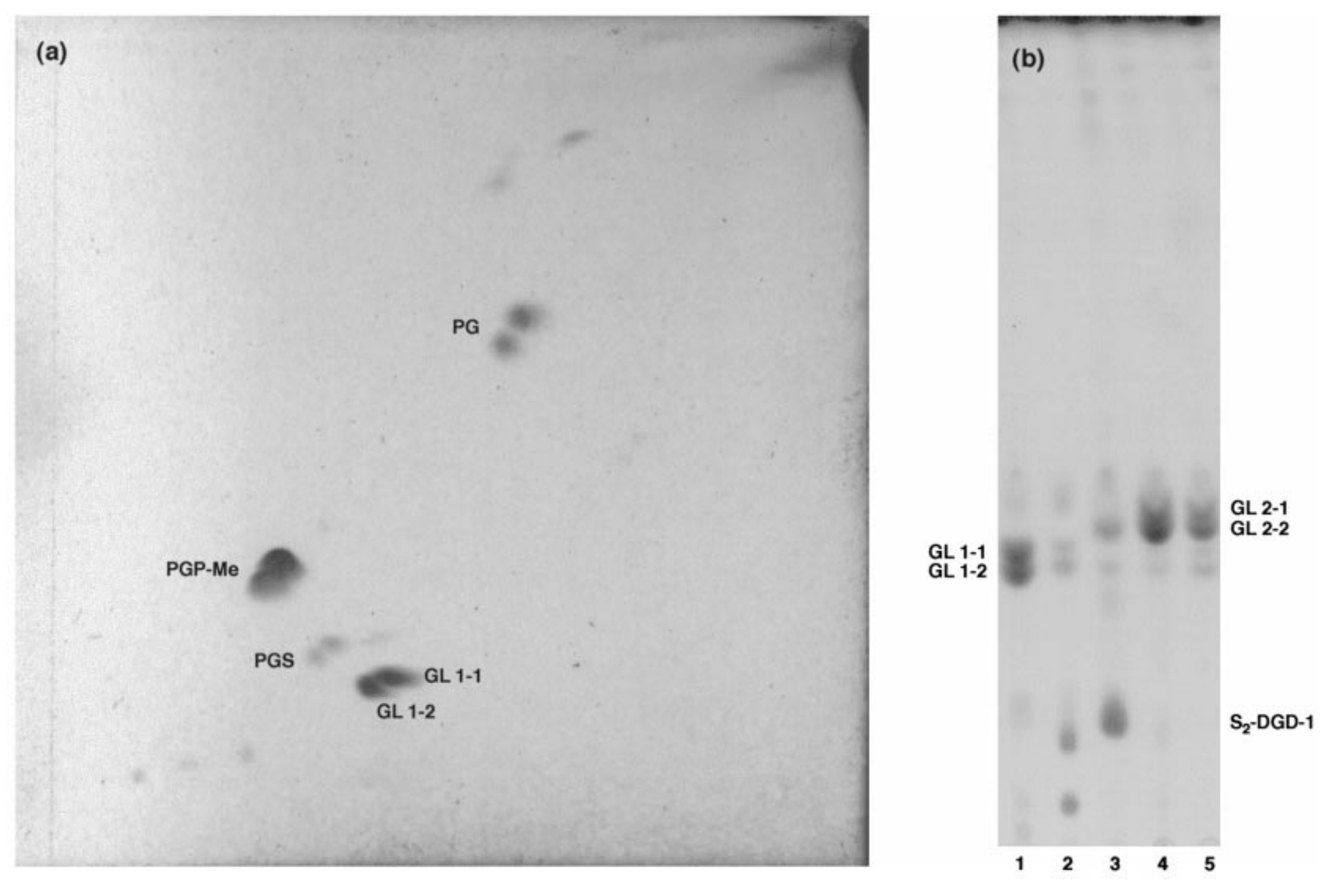

Fig. 2. TLC of polar lipids extracted from strain $X F 10^{\top}$ and some halobacteria by using the 1-naphthol/sulfuric acidethanol stain. (a) Two-dimensional TLC of polar lipids from strain XF10 ${ }^{\top}$. The plate was heated to $120^{\circ} \mathrm{C}$ to show the glycolipids and then to about $250^{\circ} \mathrm{C}$ to show all the polar lipid components. First dimension, from left to right; second dimension, from bottom to top. (b) One-dimensional TLC (from bottom to top). The plate was heated to $120^{\circ} \mathrm{C}$ to show the glycolipids. Lanes: 1, strain XF10 ${ }^{\top} ; 2$, Natrinema pellirubrum JCM 10476 ${ }^{\top} ; 3$, Haloterrigena turkmenica JCM $9101^{\top}$; 4 , Haloterrigena turkmenica JCM 9743; 5, Natrinema pallidum JCM $8980^{\top}$. GL, unidentified glycolipid; other abbreviations are defined in the text. The designation pairs (1-1 and 1-2; 2-1 and 2-2) refer to the two adjacent glycolipids in each set which may contain the same sugar residues but different diether core lipids $\left(C_{20} C_{20}\right.$ or $\left.C_{20} C_{25}\right)$. 


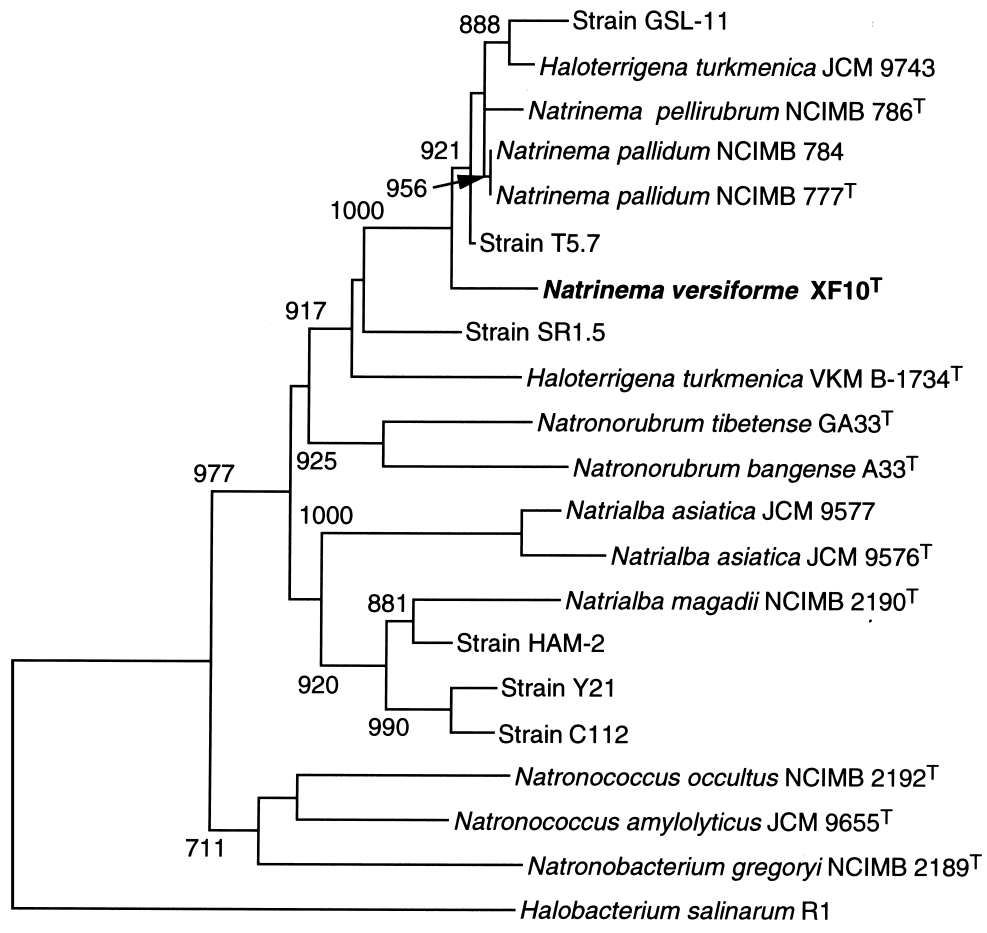

0.01
Fig. 3. Phylogenetic tree showing the position of Natrinema versiforme strain $\mathrm{XF} 10^{\top}$. The tree was constructed by the neighbour-joining method derived from the $16 \mathrm{~S}$ rRNA/rDNA sequences. The numbers indicate the bootstrap scores of 1000 trials; values greater than $70 \%$ are shown. Bar, $1 \%$ nucleotide substitution. Accession numbers of nucleotide sequences cited are as follows: Halobacterium salinarum R1, M38280; Haloterrigena turkmenica JCM 9743, D14125; Haloterrigena turkmenica VKM B-1734 ${ }^{\top}, A B 004878 ;$ Natrialba asiatica JCM 9576 ${ }^{\top}$, D14123; Natrialba asiatica JCM 9577, D14124; Natrialba magadii NCIMB 2190 ${ }^{\top}, \mathrm{X72495}$; Natrinema pallidum NCIMB $777^{\top}$, AJ002949; Natrinema pallidum NCIMB 784, AJ002948; Natrinema pellirubrum NCIMB $786^{\top}$, AJ002947; Natronobacterium gregoryi NCIMB 2189 ${ }^{\top}$, D87970; Natronorubrum bangense $A 33^{\top}, \mathrm{Y} 14028$; Natronorubrum tibetense GA33' ${ }^{\top}, \mathrm{AB} 005656$; Natronococcus amylolyticus JCM $9655^{\top}$, D43628; Natronococcus occultus NCIMB 2192' ${ }^{\top}$, Z28378; strain C112, AJ004806; strain GSL-11, D14126; strain HAM-2, AF009601; strain SR1.5, AJ002945; strain T5.7, AJ002946; and strain Y21, AJ001376.

\section{Nutrition, biochemical tests and sensitivity to antimicrobial agents}

Strain XF $10^{\mathrm{T}}$ showed anaerobic growth in the presence of nitrate but not arginine, DMSO or TMAO. Nitrate was reduced and gas formation was observed. Sulfide was formed from sulfur or thiosulfate. It exhibited positive catalase and oxidase reactions. Indole was formed. There was no hydrolysis of gelatin or casein, although weak hydrolysis of Tween 80 occurred. Hydrolysis of starch was doubtful. The strain utilized several carbohydrates. Among them, strong acid formation was observed from fructose, glucose and glycerol, and weak acid formation was observed from galactose, maltose and D-xylose; no acid was formed from mannose, D-ribose, starch or sucrose. The strain did not utilize arabinose, lactose, mannitol, raffinose, rhamnose or sorbitol. The strain was sensitive to anisomycin, bacitracin, novobiocin and rifampicin, while being insensitive to ampicillin, chloramphenicol, erythromycin, neomycin and penicillin $\mathrm{G}$.

\section{Lipid composition}

Two-dimensional TLC revealed that strain $\mathrm{XF} 10^{\mathrm{T}}$ possessed the glycerol diether analogues of phosphatidylglycerol (PG), phosphatidylglycerophosphatemethyl ester (PGP-Me), phosphatidylglycerosulfate (PGS) and some glycolipids (Fig. 2a). The core lipids were $\mathrm{C}_{20} \mathrm{C}_{20}$ and $\mathrm{C}_{20} \mathrm{C}_{25}$ diethers, as shown from the two $\mathrm{PG}$ or PGP spots. Strain $\mathrm{XF10^{ \textrm {T } }}$ showed two glycolipid spots, tentatively designated GL 1-1 and 1-2, which might correspond to molecules containing $\mathrm{C}_{20} \mathrm{C}_{20}$ and $\mathrm{C}_{20} \mathrm{C}_{25}$ diether moieties. These two glyco- lipid spots were also found in varying amounts in the two described Natrinema species, Natrinema pellirubrum JCM $10476^{\mathrm{T}}$ and Natrinema pallidum JCM $8980^{\mathrm{T}}$, as well as Haloterrigena turkmenica JCM 9743 (Fig. 2b, lanes 2, 5 and 4, respectively). Like Natrinema pellirubrum $\mathrm{JCM} 10476^{\mathrm{T}}$, strain $\mathrm{XF10}{ }^{\mathrm{T}}$ did not contain two glycolipids (tentatively designated GL 2-1 and 2-2) found in Natrinema pallidum JCM $8980^{\mathrm{T}}$ and Haloterrigena turkmenica JCM 9743 (Fig. 2b, lanes 5 and 4), whereas it lacked two glycolipids found in Natrinema pellirubrum JCM $10476^{\mathrm{T}}$ which appeared below GL 1-1 and 1-2 (Fig. 2b, lane 2). On the other hand, the type strain of Haloterrigena turkmenica, JCM 9101 ${ }^{\mathrm{T}}$, contained $\mathrm{S}_{2}$-DGD-1 [2,6-HSO ${ }_{3}-\mathrm{Man} p-\alpha(1 \rightarrow 2)-\mathrm{Gl} c p$ $\alpha(1 \rightarrow 1)$-sn-glyceroldiether] as a major glycolipid (Fig. $2 \mathrm{~b}$, lane 3 ), which was not detected in strain XF10 ${ }^{\mathrm{T}}$.

\section{Sequencing of 16S rRNA gene, alignment and reconstruction of phylogenetic tree}

Sequences of several clones containing PCR-amplified $16 \mathrm{~S}$ rDNA were determined. There were few heterogeneities among the sequences. The sequence determined was 1438 bp. Phylogenetic analysis of this 16S rDNA sequence with those of relevant halobacteria available from the database was conducted by comparing 1367 bases of each sequence, excluding gaps and uncertain bases. On the phylogenetic tree, strain $\mathrm{XF} 10^{\mathrm{T}}$, the two described Natrinema species, strains T5.7, GSL-11 (formerly L-11: Kamekura \& DyallSmith, 1995) and Haloterrigena turkmenica JCM 9743 formed a tight cluster (Fig. 3). This cluster was supported by a high bootstrap value (100\%). Strain 
Table 1. Levels of DNA-DNA relatedness between strain $X F 10^{\top}$ and related strains

\begin{tabular}{|c|c|c|c|c|c|}
\hline \multirow[t]{2}{*}{ Strain } & \multicolumn{5}{|c|}{ Relatedness (\%) with biotinylated DNA from: } \\
\hline & Strain $\mathrm{XF10}^{\mathrm{T}}$ & JCM $10476^{\mathrm{T}}$ & JCM 8980 & JCM 9743 & JCM 9101 ${ }^{\mathrm{T}}$ \\
\hline Strain $\mathrm{XF} 10^{\mathrm{T}}$ & 100 & 17 & 19 & 11 & 6 \\
\hline Natrinema pellirubrum JCM $10476^{\mathrm{T}}$ & 26 & 100 & 50 & 26 & 18 \\
\hline Natrinema pallidum JCM $8980^{\mathrm{T}}$ & 29 & 48 & 100 & 114 & 17 \\
\hline Haloterrigena turkmenica JCM 9743 & 22 & 40 & 93 & 100 & 11 \\
\hline Haloterrigena turkmenica JCM $9101^{\mathrm{T}}$ & 5 & 6 & 7 & 5 & 100 \\
\hline
\end{tabular}

XF $10^{\mathrm{T}}$ had $98.5 \%$ and $98.8 \%$ sequence similarities to the two described Natrinema species, Natrinema pellirubrum NCIMB $786^{\mathrm{T}}$ and Natrinema pallidum NCIMB $777^{\mathrm{T}}$ (also Natrinema pallidum NCIMB 784), respectively, $99 \cdot 0 \%$ to strain T5.7, and $98 \cdot 1-98 \cdot 4 \%$ to the Haloterrigena turkmenica JCM 9743/strain GSL-11 group. The closest relatives to this cluster were strain SR1.5 and Haloterrigena turkmenica VKM B-1734 ${ }^{\mathrm{T}}$ $\left(=\mathrm{JCM} 9101^{\mathrm{T}}\right)$, which had $97 \cdot 1-98 \cdot 0 \%$ and $96 \cdot 2-$ $97.2 \%$ sequence similarities, respectively, to the cluster members $(97.3 \%$ and $96.6 \%$, respectively, to strain $\left.\mathrm{XF} 10^{\mathrm{T}}\right)$. Sequence similarities between strain XF10 ${ }^{\mathrm{T}}$ and the rest of halophilic archaea compared were $90 \cdot 5-95 \cdot 7 \%$.

\section{G + C content and DNA-DNA hybridization}

The $\mathrm{G}+\mathrm{C}$ content of total DNA of strain $\mathrm{XF} 10^{\mathrm{T}}$ was $64.2 \mathrm{~mol} \%$, which is similar to that of Natrinema pellirubrum JCM $10476^{\mathrm{T}}$, Natrinema pallidum JCM $8980^{\mathrm{T}}$ and Haloterrigena turkmenica JCM 9743 (62.9, 63.9 and $64.4 \mathrm{~mol} \%$, respectively). The DNA-DNA hybridization results are shown in Table 1. Low levels of DNA-DNA hybridization were observed between strain XF10 $10^{\mathrm{T}}$ and the two described Natrinema species (17-29\%), and Haloterrigena turkmenica JCM 9743 $(11-22 \%)$, as well as Haloterrigena turkmenica JCM $9101^{\mathrm{T}}(5-6 \%)$. The DNA-DNA hybridization values between Natrinema pellirubrum JCM $10476^{\mathrm{T}}$ and Natrinema pallidum JCM $8980^{\mathrm{T}}$ were almost the same as that reported by Ross \& Grant (1985) (50\%).

\section{DISCUSSION}

Strain $\mathrm{XF} 10^{\mathrm{T}}$ was isolated from a neutral salt lake in the northwest part of China. It was isolated along with many other halobacterial strains (and some eubacteria) after enrichment in complex medium containing $20 \%$ $\mathrm{NaCl}$.

On the phylogenetic tree based on 16S rDNA sequences, strain $\mathrm{XF} 10^{\mathrm{T}}$ clustered with the two described Natrinema species as well as strains T5.7, GSL11 and Haloterrigena turkmenica JCM 9743 ( $\geqslant 98 \cdot 1 \%$ sequence similarities). This cluster is still phylogenetically coherent when compared with several halobacterial genera such as Halorubrum $(\geqslant 92.8 \%$ sequence similarity), Natrialba $(\geqslant 93 \cdot 3 \%)$ and Natronorubrum (95.2\%) (McGenity \& Grant, 1995; Kamekura et al., 1997; Xu et al., 1999). Therefore, all members of this cluster, including strain $\mathrm{XF} 10^{\mathrm{T}}$, should belong to the genus Natrinema, which was proposed validly in 1998 (McGenity et al., 1998). Although Haloterrigena turkmenica JCM 9743 should be renamed, this strain is still in taxonomic confusion as discussed below. The presence of the two unidentified glycolipid spots shared by the two described Natrinema species would support assignment of strain XF10 $10^{\mathrm{T}}$ to the genus Natrinema. Strain XF10 was also similar to the two described Natrinema species in possessing $\mathrm{C}_{20} \mathrm{C}_{25}$ core lipids (McGenity et al., 1998; Kamekura \& Dyall-Smith, 1995). Although strain $\mathrm{XF10} 0^{\mathrm{T}}$ (and the Natrinema species) showed slightly high 16S rDNA sequence similarity to Haloterrigena turkmenica VKM B-1734 ${ }^{\mathrm{T}}(96 \cdot 6 \%)$, the latter had a significant amount of $\mathrm{S}_{2}$-DGD-1 as a characteristic glycolipid (Ventosa et al., 1999), which suggested that strain $\mathrm{XF} 10^{\mathrm{T}}$ should not belong to the genus Haloterrigena.

In terms of phenotypic properties, the difference between strain $\mathrm{XF10}$ and the two described Natrinema species (McGenity et al., 1998) is clear despite the close phylogenetic relationships. Strain XF10 ${ }^{\mathrm{T}}$ does not exhibit the typical rod shape of the two described Natrinema species and it differs from them in several biochemical and physiological properties as shown in Table 2. Moreover, strain XF10 ${ }^{\mathrm{T}}$ shows some differences in polar lipid composition from both the two described Natrinema species. Low DNA-DNA relatedness between strain $\mathrm{XF} 10^{\mathrm{T}}$ and the two described Natrinema species clearly indicated that strain $\mathrm{XF} 10^{\mathrm{T}}$ is independent from them. Likewise, differences in polar lipid composition (Fig. 2b, lane 4) and low DNA-DNA relatedness between strain XF $10^{\mathrm{T}}$ and Haloterrigena turkmenica JCM 9743 support the proposal that strain $\mathrm{XF} 10^{\mathrm{T}}$ is also separate from Haloterrigena turkmenica JCM 9743. According to the properties described above, strain $\mathrm{XF} 10^{\mathrm{T}}$ should be a new species of the genus Natrinema, and the name Natrinema versiforme sp. nov. is proposed. The type strain is strain XF10 ${ }^{\mathrm{T}}$, which has been deposited in the Japan Collection of Microorganisms, RIKEN (The Institute of Physical and Chemical Research), Saitama, 
Table 2. Major differential properties between strain $\mathrm{XF} 10^{\top}$ and Natrinema species

\begin{tabular}{|lccc|}
\hline Property & Strain XF10 & $\begin{array}{c}\text { Natrinema } \\
\text { pellirubrum* }\end{array}$ & $\begin{array}{c}\text { Natrinema } \\
\text { pallidum* }\end{array}$ \\
\hline Cell morphology & Pleomorphic & Rod & Rod \\
Anaerobic growth with nitrate & + & - & - \\
Gas formation from nitrate & + & - & - \\
Indole formation & + & + & - \\
Hydrolysis of gelatin & - & + & + \\
Utilization of: & - & + & + \\
$\quad$ Lactose & + & - & - \\
Ribose & + & Slight \\
Sensitivity to rifampicin & & & \\
\hline
\end{tabular}

* From McGenity et al. (1998).

Japan as JCM $10478^{\mathrm{T}}$, and in the Institute of Microbiology, Chinese Academy of Sciences (CAS), Beijing, PR China as AS $1.2365^{\mathrm{T}}$. It is also registered as ANMR $0149^{\mathrm{T}}$ as the strain belongs to the 'Asian Network on Microbial Research' project.

Recently, it was shown that Haloterrigena turkmenica JCM 9743 (formerly Halobacterium trapanicum JCM 9743), which had been thought to be the descendant of the original type strain of Halobacterium trapanicum $\left(\mathrm{NRC} 34021^{\mathrm{T}}\right)$, was not identical to the original strain (Kamekura, 1998). Ventosa et al. (1999) regarded it as a strain of Haloterrigena turkmenica, although this needs to be reconsidered. Our DNA-DNA hybridization data revealed that Haloterrigena turkmenica JCM 9743 was unrelated to Haloterrigena turkmenica JCM $9101^{\mathrm{T}}$ (an equivalent strain of VKM B-1734 ${ }^{\mathrm{T}}$ ) (Table 1). Moreover, the two strains differed in their polar lipid composition (Ventosa et al., 1999; also shown in Fig. 2b, lanes 3 and 4), and the $16 \mathrm{~S}$ rDNA sequence similarity between both the strains was too low $(96.6 \%)$ for inclusion in the same species. On the basis of the very high DNA-DNA hybridization value (Table 1), it appears that Haloterrigena turkmenica JCM 9743 and Natrinema pallidum JCM $8980^{\mathrm{T}}$ are the same species. However, a final conclusion should not be drawn until a thorough phenotypic comparison with Natrinema pallidum is accomplished.

Inclusion of strain $\mathrm{XF} 10^{\mathrm{T}}$ as a new species in the genus Natrinema seems to require the amendment of the description of this genus, which is given below.

\section{Amended description of the genus Natrinema McGenity, Gemmell and Grant 1998}

Cells rod-shaped, $1-5 \mu \mathrm{m}$ by $0.6-1 \cdot 0 \mu \mathrm{m}$, or pleomorphic. Cells lyse at low $\mathrm{NaCl}$ concentration $(<1 \cdot 0$ $\mathrm{M})$. Colonies light orange-red or pale orange, $0 \cdot 5-$ $2.0 \mathrm{~mm}$ in diameter, smooth, circular, convex. Gramnegative. Chemo-organotroph. Some species are strict aerobes, whereas others show anaerobic growth with nitrate. Nitrogen source: Casamino acids. Carbon sources: Casamino acids and certain sugars. Requires at least $1.5-1.7 \mathrm{M} \mathrm{NaCl}$ for growth; optimum 3.4 $4 \cdot 3 \mathrm{M} \mathrm{NaCl}$. Optimum $\mathrm{pH}$ around 7.0. Possesses $\mathrm{C}_{20} \mathrm{C}_{20}$ and $\mathrm{C}_{20} \mathrm{C}_{25}$ diether core lipids (Ross et al., 1985; Ross \& Grant, 1985). Possesses several unidentified glycolipids (Ross et al., 1985). Sensitive to anisomycin, bacitracin and novobiocin. Type species: Natrinema pellirubrum.

\section{Description of Natrinema versiforme sp. nov.}

Natrinema versiforme (ver.si.for'me. L. neut. adj. versiforme of various shapes; the various-shaped Natrinema).

Cells non-motile and pleomorphic. Lyse in dilute medium containing less than $1.0 \mathrm{M} \mathrm{NaCl}$ or in distilled water. Colonies light red, $0.5-1.0 \mathrm{~mm}$ in diameter, smooth, circular and elevated. Requires at least $1.5 \mathrm{M}$ $\mathrm{NaCl}$ for growth; optimum 3.4-4.3 M (in the presence of $0.15 \mathrm{M} \mathrm{MgCl}_{2}$ ). Growth occurs at $0.005-0.5 \mathrm{M}$ $\mathrm{MgCl}_{2}$; optimum around $0.15 \mathrm{M}$. Temperature range for growth $20-53{ }^{\circ} \mathrm{C}$, optimum $37-46^{\circ} \mathrm{C}$. $\mathrm{pH}$ range for growth $6 \cdot 0-8 \cdot 0$; optimum $6 \cdot 5-7 \cdot 0$. Chemo-organotrophic. Anaerobic growth in the presence of nitrate. Carbon sources: Casamino acids and several sugars, such as fructose, glucose, glycerol (with strong acid formation), galactose, maltose, mannose, D-ribose, sucrose and D-xylose, but not lactose. Reduces nitrate and forms gas. Forms sulfide from sulfur or thiosulfate. Forms indole. Does not hydrolyse gelatin or casein. Starch hydrolysis doubtful and weak hydrolysis of Tween 80. Possesses $\mathrm{C}_{20} \mathrm{C}_{20}$ and $\mathrm{C}_{20} \mathrm{C}_{25}$ diether core lipids and some unidentified glycolipids. Possesses phospholipids: PG, PGP-Me and PGS. Sensitive to anisomycin, bacitracin, novobiocin and rifampicin. Insensitive to ampicillin, chloramphenicol, erythromycin, neomycin and penicillin G. Type strain: XF10 $\left(=\mathrm{JCM} 10478^{\mathrm{T}}=\operatorname{AS} 1.2365^{\mathrm{T}}=\right.$ ANMR $\left.0149^{\mathrm{T}}\right)$.

\section{ACKNOWLEDGEMENTS}

We thank Liu Dali for skilled assistance. This study was partially supported by special coordination funds for promoting science and technology of the Science and Technology Agency of the Japanese Government. 


\section{REFERENCES}

Cline, S. W., Schalkwyk, L. C. \& Doolittle, W. D. (1989). Transformation of the archaebacterium Halobacterium volcanii with genomic DNA. J Bacteriol 171, 4987-4991.

Dittmer, J. C. \& Lester, R. L. (1964). A simple, specific spray for the detection of phospholipids on thin-layer chromatograms. $J$ Lipid Res 5, 126-127.

Dussault, H. P. (1955). An improved technique for staining red halophilic bacteria. J Bacteriol 70, 484-485.

Ezaki, T., Hashimoto, H. \& Yabuuchi, E. (1989). Fluorometric deoxyribonucleic acid-deoxyribonucleic acid hybridization in microdilution wells as an alternative to membrane filter hybridization in which radioisotopes are used to determine genetic relatedness among bacterial strains. Int $J$ Syst Bacteriol 39, 224-229.

Felsenstein, J. (1985). Confidence limits on phylogenies: an approach using the bootstrap. Evolution 39, 783-791.

Grant, W. D. \& Larsen, H. (1989). Extremely halophilic archaeobacteria, order Halobacteriales ord. nov. In Bergey's Manual of Systematic Bacteriology, vol. 3, pp. 2216-2233. Edited by J. T. Staley, M. P. Bryant, N. Pfennig \& J. G. Holt. Baltimore: Williams \& Wilkins.

Ihara, K., Watanabe, S. \& Tamura, T. (1997). Haloarcula argentinensis sp. nov. and Haloarcula mukohataei sp. nov., two new extremely halophilic archaea collected in Argentina. Int $J$ Syst Bacteriol 47, 73-77.

Kamekura, M. (1993). Lipids of extreme halophiles. In The Biology of Halophilic Bacteria, pp. 135-161. Edited by R. H. Vreeland \& L. I. Hochstein. Boca Raton: CRC Press.

Kamekura, M. (1998). Diversity of extremely halophilic bacteria Extremophiles 2, 289-295.

Kamekura, M. \& Dyall-Smith, M. L. (1995). Taxonomy of the family Halobacteriaceae and the description of two genera Halorubrobacterium and Natrialba. J Gen Appl Microbiol 41, 333-350.

Kamekura, M., Dyall-Smith, M. L., Upasani, V., Ventosa, A. \& Kates, M. (1997). Diversity of alkaliphilic halobacteria: proposals for transfer of Natronobacterium vacuolatum, Natronobacterium magadii, and Natronobacterium pharaonis to Halorubrum, Natrialba, and Natronomonas gen. nov., respectively, as Halorubrum vacuolatum comb. nov., Natrialba magadii comb. nov., and Natronomonas pharaonis comb. nov., respectively. Int J Syst Bacteriol 47, 853-857.

McGenity, T. J. \& Grant, W. D. (1995). Transfer of Halobacterium saccharovorum, Halobacterium sodomense, Halobacterium trapanicum NRC 34021 and Halobacterium lacusprofundi to the genus Halorubrum gen. nov. as Halorubrum saccharovorum comb. nov., Halorubrum sodomense comb. nov., Halorubrum trapanicum comb. nov., and Halorubrum lacusprofundi comb. nov. Syst Appl Microbiol 18, 237-243.

McGenity, T. J., Gemmell, R. T. \& Grant, W. D. (1998). Proposal of a new halobacterial genus Natrinema gen. nov., with two species Natrinema pellirubrum nom. nov. and Natrinema pallidum nom. nov. Int J Syst Bacteriol 48, 1187-1196.
Montalvo-Rodríguez, R., Vreeland, R. H., Oren, A., Kessel, M., Betancourt, C. \& López-Garriga, J. (1998). Halogeometricum borinquense gen. nov., sp. nov., a novel halophilic archaeon from Puerto Rico. Int J Syst Bacteriol 48, 1305-1312.

Oren, A., Ventosa, A. \& Grant, W. D. (1997). Proposed minimal standards for description of new taxa in the order Halobacteriales. Int J Syst Bacteriol 47, 233-238.

Ross, H. N. M. \& Grant, W. D. (1985). Nucleic acid studies on halophilic archaebacteria. J Gen Microbiol 131, 165-173.

Ross, H. N. M., Grant, W. D. \& Harris, J. E. (1985). Lipids in archaebacterial taxonomy. In Chemical Methods in Bacterial Systematics, pp. 289-300. Edited by M. Goodfellow \& D. E. Minnikin. London: Academic Press.

Saitou, N. \& Nei, M. (1987). The neighbor-joining method: a new method for reconstructing phylogenetic trees. Mol Biol Evol 4, 406-425.

Sehgal, S. N. \& Gibbons, N. E. (1960). Effect of metal ions on the growth of Halobacterium cutirubrum. Can J Microbiol 6, 165-169.

Smibert, R. M. \& Krieg, N. R. (1981). General characterization. In Manual of Methods for General Bacteriology, pp. 409-443. Edited by P. Gerhardt, R. G. E. Murray, R. N. Costilow, E. W. Nester, W. A. Wood, N. R. Krieg \& G. B. Phillips. Washington, DC: American Society for Microbiology.

Tamaoka, J. (1994). Determination of DNA base composition. In Chemical Methods in Prokaryotic Systematics, pp. 463-470. Edited by M. Goodfellow \& A. G. O'Donnell. Chichester: Wiley.

Thompson, J. D., Higgins, D. G. \& Gibson, T. J. (1994). CLUSTAL $\mathrm{W}$ : improving the sensitivity of progressive multiple sequence alignment through sequence weighting, position-specific gap penalties and weight matrix choice. Nucleic Acids Res 22, 4673-4680.

Tian, X., Xu, Y., Liu, H. \& Zhou, P. (1997). New species of Natronobacterium. Acta Microbiol Sin 37, 1-6.

Ventosa, A., Gutiérez, M. C., Kamekura, M. \& Dyall-Smith, M. L. (1999). Proposal to transfer Halococcus turkmenicus, Halobacterium trapanicum JCM 9743 and strain GSL-11 to Haloterrigena turkmenica gen. nov., comb. nov. Int J Syst Bacteriol 49, 131-136.

Wang, D., Zhou, P., Tian, X. \& Ma, G. (1984). Identification of new species of extreme halophilic bacteria. Acta Microbiol Sin 24, 304-309.

Xu, Y., Liu, H. \& Zhou, P. (1995). Nucleotide sequence of the $16 \mathrm{~S}$ rRNA from an archaea, Haloarcula aidinensis strain B2. Acta Microbiol Sin 35, 77-85.

Xu, Y., Zhou, P. \& Tian, X. (1999). Characterization of two novel haloalkaliphilic archaea, Natronorubrum bangense gen. nov., sp. nov. and Natronorubrum tibetense gen. nov., sp. nov. Int $J$ Syst Bacteriol 49, 261-266.

Zhou, P., Tian, X., Ma, Y., Xiao, C. \& Wang, D. (1990). An extreme haloalkaligenous bacterium. Acta Microbiol Sin 30, 1-6.

Zhou, P., Xu, Y., Xiao, C., Ma, Y. \& Liu, H. (1994). New species of Haloarcula. Acta Microbiol Sin 34, 89-95. 